\title{
Fixador esquelético pino-resina acrílica e enxerto ósseo esponjoso no tratamento de complicações secundárias à imobilização inadequada de fratura do rádio e ulna em cães
}

\author{
Acrylic-pin external fixator and cancellous bone graft in the treatment of complications \\ caused by inadequate immobilization of radius and ulna fracture in dogs
}

\author{
Sheila Canevese Rahal ${ }^{1}$ Khadije Hette $^{2}$ Caroline de Abreu Estanislau $^{3}$ \\ Luiz Carlos Vulcano ${ }^{4}$ Alfredo da Maia Feio ${ }^{5}$ Alexandre Luiz Costa Bicudo ${ }^{6}$
}

RESUMO

\begin{abstract}
O objetivo do estudo foi avaliar a eficácia do fixador esquelético pino-resina, configuração tipo II, coadjuvado pelo enxerto ósseo esponjoso autólogo, no tratamento das complicações secundárias à imobilização inadequada de fraturas do rádio e ulna em dez cães, com peso entre 1,8 e 33,6kg. Detectou-se não-união $(n=4)$, osteomielite $(n=1)$, má-união $(n=1)$, falência ou quebra de implante $(n=4)$, sendo $60 \%$ das lesões referente ao uso prévio de pino intramedular no rádio. A montagem do fixador foi realizada com transfixação de pinos lisos em sua maioria angulados, cujas extremidades excedentes foram dobradas e estabilizadas com resina acrílica. Em todos os casos, utilizou-se enxerto esponjoso autólogo fresco, após debridamento do foco de fratura. O tempo de permanência do aparelho variou entre 45 dias e 5 meses e a maior complicação foi o afrouxamento dos pinos transfixantes. A consolidação das fraturas ocorreu por formação de calo periosteal de mínimo a moderado, indicando boa rigidez da montagem.
\end{abstract}

Palavras-chave: ortopedia, cirurgia, não-união, osteomielite, polimetilmetacrilato.

\section{ABSTRACT}

The aim of this study was to evaluate the acrylic-pin external fixator, type II-configuration, and cancellous bone autograft for treating complications of radius and ulna fractures in ten dogs weighing between 1.8 and $33.6 \mathrm{~kg}$. Nonunion $(n=4)$, osteomyelitis ( $n=1)$, malunion ( $n=1)$, failure or breakage of implant $(n=4)$ were detected, and $60 \%$ of them were associated with previous intramedullary pin placement in the radius. The fixator frame was constructed using most of the smooth transfixation pins angled. The fixation rods were constructed by placing acrylic resin over the ends of the transfixation pins that were previously bent. In all cases fresh cancellous bone autograft was used after cleaning of the fracture site. The permanence time of the external fixator ranged from 45 days to 5 months, and the most important complication was pin loosening. Fracture healing was by minimal to moderate periosteal callus, suggesting good rigidity of the frame configuration.

Key words: orthopedic, surgery, nonunion, osteomyelitis, polymethylmethacrylate.

\section{INTRODUÇÃO}

As fraturas de rádio e ulna são comuns em cães e a maioria ocorre nos terços médio e distal dos ossos (GORSE, 1998). A consolidação dessas fraturas pode ser problemática e a incidência de complicações é relativamente alta, tendo sido relatada união atrasada, não-união, má-união, deformidades de crescimento e rigidez articular, entre outras (LAPPIN et al., 1983; RUDD

\footnotetext{
${ }^{1}$ Departamento de Cirurgia e Anestesiologia Veterinária, Faculdade de Medicina Veterinária e Zootecnia, Unesp Botucatu. Rubião Júnior s/n, 18618000, Botucatu, SP, Brasil. Email: sheilacr@fmvz.unesp.br. Autor para correspondência.

${ }^{2}$ Autônomo

${ }^{3}$ Curso de Medicina Veterinária da Faculdade de Medicina Veterinária e Zootecnia (FMVZ), Unesp, Botucatu, SP, Brasil.

${ }^{4}$ Departamento de Reprodução Animal e Radiologia Veterinária, Faculdade de Medicina Veterinária e Zootecnia, Unesp Botucatu, SP, Brasil.

${ }^{5}$ Pós-graduação da FMVZ, Unesp, Botucatu, SP, Brasil.

${ }^{6} \mathrm{FMVZ}$, Unesp Botucatu, SP, Brasil.
} 
\& WHITEHAIR, 1992). O pino intramedular não deve ser utilizado no rádio, visto que o acesso limitado para inserção geralmente lesa a superfície articular, e o canal medular pequeno e a conformação cranial não proporcionam resistência às forças de cisalhamento e envergadura (BOUDRIEU, 2002). A coaptação externa é indicada apenas em fraturas transversas ou oblíquas curtas que não estejam próximas à articulação, porém em cães de raças pequenas, ela não deve ser empregada por causa da alta frequiência de complicações (LAPPIN et al., 1983; RUDD \& WHITEHAIR, 1992; BOUDRIEU, 2002).

A fixação esquelética externa é uma das técnicas de escolha para o tratamento de fraturas do rádio e ulna por ser versátil, evitar implante de metal no local da fratura, permitir acesso no manejo de ferida, manter o comprimento do membro na presença de defeitos ósseos segmentares, facilitar a aplicação precoce ou tardia do enxerto e ser de fácil remoção após a consolidação (RUDD \& WHITEHAIR, 1992; WATERS et al., 1993; GORSE, 1998). Como é possível obter rígida fixação, com mínima invasão dos tecidos moles e sem lesão do suprimento sangüíneo, é considerada técnica ideal para o tratamento de união atrasada ou de não-união (LINCOLN, 1992).

Todos os tipos de configurações têm sido utilizados em fraturas do rádio e ulna, sendo que a fixação primária geralmente requer configuração bilateral (tipo II) ou em situações desafiadoras a bilateral biplanar (GORSE, 1998). As configurações podem ser construídas com garras de conexão e barras de metal ou alumínio, ou apenas com barras de acrílico (WATERS et al., 1993; HARARI et al., 1998; HULSE \& JOHNSON, 2002). O uso de fixadores esqueléticos externos utilizando barras conectantes de acrílico tornou-se bastante popular em medicina veterinária pelo baixo custo, versatilidade e facilidade de aplicação (OKRASINSKI et al., 1991; ROSS \& MATTHIESEN, 1993), sendo uma opção de tratamento para cães pertencentes a proprietários com baixo poder aquisitivo. Além disso, não há necessidade de alinhamento dos pinos como no uso da barra de metal (LEWIS \& BLOOMBERG, 1994; HARARI et al., 1998). Nos Estados Unidos foi desenvolvido um sistema comercial, com uso de tubos para colocação da resina (HULSE \& JOHNSON, 2002). Um estudo biomecânico mostrou que a barra acrílica de $2 \mathrm{~cm}$ de diâmetro foi superior em cargas de compressão e cisalhamento à barra de aço de $4,8 \mathrm{~mm}$, que é a tradicional do sistema Kirschner-Ehmer (K-E) de tamanho médio (OKRASINSKI et al., 1991).

O trabalho teve por objetivo avaliar a eficácia do fixador esquelético pino-resina, configuração tipo II, coadjuvado pelo enxerto esponjoso autólogo, no tratamento das complicações secundárias à imobilização inadequada de fraturas do rádio e ulna em cães.

\section{MATERIAL E MÉTODOS}

Foram utilizados 10 cães portadores de complicações na consolidação de fraturas do rádio e ulna (não-união, osteomielite, má-união, falência ou quebra de implante) selecionados durante o atendimento do Serviço de Cirurgia de Pequenos Animais da Faculdade de Medicina Veterinária e Zootecnia, Unesp Botucatu (Tabela 1), em um período de aproximadamente 6 anos.

Os procedimentos cirúrgicos foram efetuados com os animais sob anestesia geral inalatória. O foco de fratura foi abordado por acesso medial limitado e as extremidades fraturadas curetadas e reduzidas. Todas as lesões foram tratadas com fixador esquelético pino-resina, configuração tipo II, com um mínimo dois e o máximo de quatro pinos lisos transfixando os fragmentos proximal e distal da fratura do rádio. O diâmetro dos pinos de Steinmann ou dos fios de Kirschner foi em torno de $20 \%$ do diâmetro ósseo. Estes foram inseridos através do tecido mole intacto, em sua maioria angulados em relação ao eixo longitudinal ósseo, e transfixados de medial para lateral ou, em cães de raças pequenas, de craniomedial para caudolateral. Para aplicação, utilizou-se perfurador manual com manivela ${ }^{a}$. As extremidades excedentes dos pinos foram dobradas em relação eixo longitudinal do próprio pino (ângulo interno de $90^{\circ}$ a $120^{\circ}$ ) e em direção ao foco de fratura. Em seguida, aplicou-se sobre essas a resina acrílica em fase pastosa de forma a constituir uma barra. Durante a polimerização da resina, os pinos transfixantes foram irrigados com solução salina $0,9 \%$, para minimizar os efeitos térmicos. Por tratar-se de resina não estéril, a manipulação e aplicação foram efetuadas por um assistente e a ferida cirúrgica foi mantida protegida. Após a imobilização dos fragmentos ósseos, aplicou-se, no foco de fratura, enxerto esponjoso autólogo, colhido da crista ilíaca.

No pré-operatório imediato e por mais cinco a sete dias de pós-operatório, utilizou-se antibiótico de amplo espectro (cefalotina $25 \mathrm{mg} \mathrm{kg}^{-1}$ via IV a cada 8 horas, ou cefalexina $30 \mathrm{mg} \mathrm{kg}^{-1}$ via oral a cada 8 horas, ou ampicilina $10 \mathrm{mg} \mathrm{kg}^{-1}$ via oral ou IV a cada 8 horas). No caso de osteomielite, a cefalexina foi mantida por 30 dias. Cloridrato de buprenorfina ( $15 \mu \mathrm{g} \mathrm{kg}^{-1}$, IM) foi aplicado antes e 12 horas após o procedimento cirúrgico. No pósoperatório, foi utilizada flunixina meglumina $\left(1,1 \mathrm{mg} \mathrm{kg}^{-1}\right.$ via subcutânea), por até quatro dias, ou carprofeno $(2,2 \mathrm{mg}$ $\mathrm{kg}^{-1}$, via oral, a cada 12 horas) por cinco a sete dias. Os locais de entrada e saída dos pinos foram limpos diariamente ou em dias alternados com solução fisiológica e manteve-se, ao redor destes, gaze embebida com 
solução de nitrofurazona líquida. O fixador foi totalmente envolvido com atadura elástica de crepe. Foram realizados exames radiográficos periódicos para avaliar a evolução e o momento da consolidação da fratura, bem como para detectar complicações oriundas da utilização do fixador. Este foi removido, quando da constatação da consolidação, por secção e posterior tração dos pinos com uso de alicate. Se necessário, após a remoção do fixador, utilizava-se tala com suporte de peso ao solo por alguns dias ou solicitava-se restrição de atividade do cão. A função do membro, após a remoção do fixador, foi graduada de acordo com a escala de FOX et al. (1995): excelente - função normal do membro; bom - leve claudicação apenas após exercício; satisfatório - leve a moderada claudicação, mas consistente suporte de peso; ruim - nenhum suporte de peso.

\section{RESULTADOS}

Em todos os animais, a consolidação das fraturas ocorreu com formação de calo periosteal que variou de mínimo a moderado (Figuras 1 e 2). Embora o rádio estivesse consolidado, em dois cães, a ulna ainda apresentava linha de fratura. Na maioria dos casos, ocorreu o afrouxamento de um ou mais pinos transfixantes observado radiograficamente por osteólise, com ou sem reação periosteal, e clinicamente por aumento da secreção nos pontos de emergência dos pinos. Nesses casos, o proprietário foi instruído a reduzir a atividade do cão e efetuar limpeza mais freqüente nos locais de emergência dos pinos. Quando necessário, foi instituída profilaxia antimicrobiana. Mesmo com a constatação da osteólise, o fixador foi removido somente após a consolidação. A exceção foram os cães 7 e 8 que apresentaram severa mobilidade do fixador respectivamente aos 2 meses e 2 meses e meio de pós-operatório, visto a maioria dos pinos estarem comprometidos. Nestes casos, aplicou-se tala com apoio do membro por mais um mês.

Nenhum caso apresentou sinais indicativos de infecção. No cão 4, aplicou-se tala de proteção com apoio do membro por alguns meses, a pedido do proprietário e devido ao comportamento do animal, que freqüentemente saltava de locais elevados. Nos cães 4, 7 e 10, a consolidação ocorreu com leve desvio caudal. Formação de sinostose radioulnar foi detectada em diferentes intensidades nos casos 3, 4, 8, 9e 10 (Figura 2).

O tempo de permanência do fixador e a última avaliação do resultado funcional encontra-se na tabela 1.

\section{DISCUSSÃO}

O uso de pino intramedular ou a coaptação externa com tala foram responsáveis pela maioria das complicações prévias, similar ao referido por outros autores (LAPPIN et al., 1983; RUDD \& WHITEHAIR, 1992; BOUDRIEAU, 2002). Embora união retardada, não-união e desvio angular possam ocorrer com o emprego da fixação esquelética externa (LAPPIN et al., 1983; JOHNSON et al., 1989; ROSS \& MATTHIESEN, 1993), muitas vezes elas estão associadas com a sua má utilização (LAPPIN et al., 1983), como provavelmente ocorreu no caso 10 , já que os pinos transfixantes foram posicionados muito próximo ao foco de fratura. Vale salientar que numa segunda aplicação do fixador é essencial a inserção dos pinos transfixantes em locais diversos aos previamente usados, de forma a evitar afrouxamento prematuro e fratura iatrogênica.

Optou-se pela configuração tipo II porque os pinos utilizados eram lisos e, por isso, proporcionam menor estabilidade na interface pino-osso (ANDERSON et al., 1997). Apesar dos pinos inevitavelmente penetrarem os músculos na face lateral (GORSE, 1998), não se detectaram complicações associadas a esse fato. Especialmente em cães de porte pequeno, o formato retangular do rádio dificulta a inserção dos pinos da face medial para lateral e

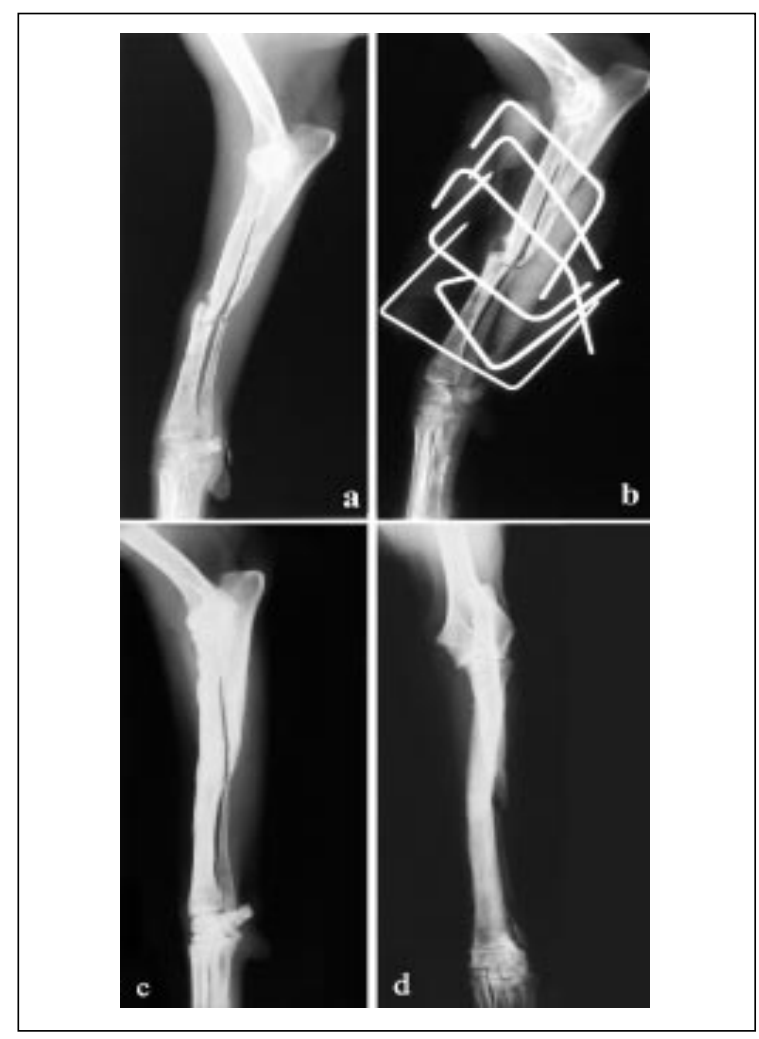

Figura 1 - Cão 1 portador de não-união de fratura diafisária média do rádio e ulna esquerdos com seis meses de evolução. Imagens radiográficas em posição lateral no pré-operatório (a) e pós-operatório imediato (b), e em posições lateral (c) e craniocaudal (d) 1 ano e 6 meses após a remoção do fixador. Nota-se o bom alinhamento do rádio e a não-união da ulna (c, d).

Ciência Rural, v.35, n.5, set-out, 2005. 


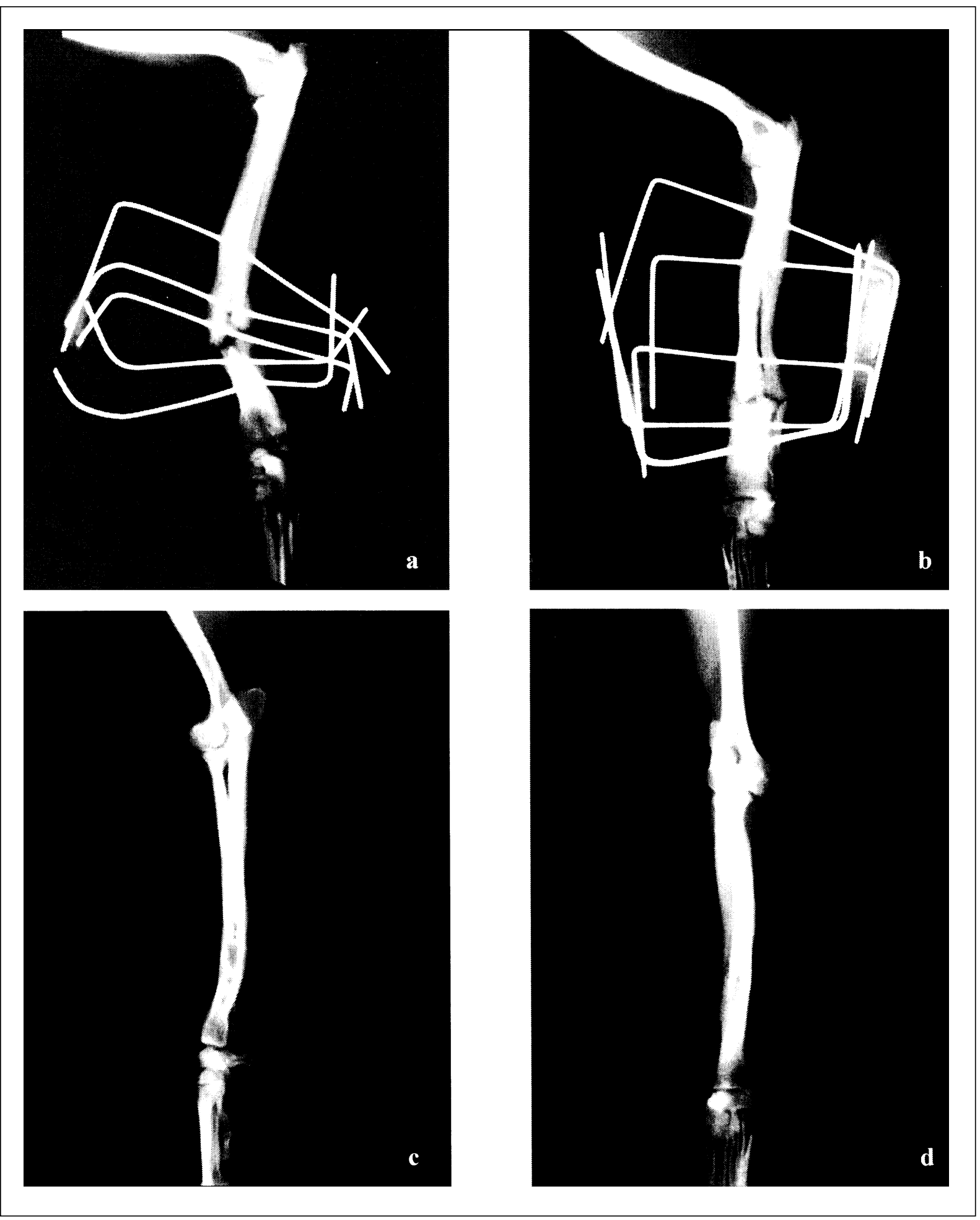

Figura 2 - Cão 10 portador de fratura oblíqua curta do terço médio-distal do rádio e ulna direitos tratado com tala e fixador externo, totalizando 2 meses de evolução. Imagens radiográficas em posição lateral oblíqua: (a) pré-operatório com desvio do eixo ósseo e pinos transfixantes aplicados muito próximos ao foco de fratura, estando um quebrado; (b) 1 mês de pós-operatório mostrando formação de calo ósseo periosteal. Imagens radiográficas em posição lateral (c) e craniocaudal (d) 1 ano e 7 meses após a remoção do fixador. Observa-se a consolidação com leve desvio caudal (c) e presença de sinostose radioulnar.

Ciência Rural, v.35, n.5, set-out, 2005. 
Tabela 1 - Identificação do cão (raça, idade, sexo, peso), tratamento prévio e tempo de evolução, tipo de complicação, número de pinos transfixantes proximais e distais ao foco de fratura, tempo de permanência do fixador esquelético externo e resultado funcional.

\begin{tabular}{|c|c|c|c|c|c|}
\hline $\begin{array}{l}\text { Identificação } \\
\text { do cão }\end{array}$ & $\begin{array}{l}\text { Tratamento prévio e } \\
\text { tempo de evolução }\end{array}$ & Tipo de complicação & $\begin{array}{l}\text { Número de pinos } \\
\text { transfixantes }\end{array}$ & $\begin{array}{l}\text { Tempo de } \\
\text { permanência } \\
\text { do fixador }\end{array}$ & $\begin{array}{l}\text { Resultado funcional/ } \\
\text { última avaliação }\end{array}$ \\
\hline $\begin{array}{l}\text { Sem raça } \\
\text { definida, } 5 \\
\text { anos, macho, } \\
11,5 \mathrm{~kg} \\
\text { (caso } 1 \text { ) }\end{array}$ & $\begin{array}{l}\text { Fixador esquelético } \\
\text { externo e posteriormente } \\
\text { tala, totalizando } \\
\text { aproximadamente } 6 \text { meses } \\
\text { de evolução. }\end{array}$ & $\begin{array}{l}\text { Não-união distrófica de fratura } \\
\text { diafisária média do rádio e ulna } \\
\text { esquerdos. }\end{array}$ & $\begin{array}{l}3 \text { pinos } \\
\text { proximais e } 3 \\
\text { distais }\end{array}$ & 5 meses & $\begin{array}{l}\text { Excelente/ } 1 \text { ano e } 6 \\
\text { meses }\end{array}$ \\
\hline $\begin{array}{l}\text { Poodle, } 2 \text { anos } \\
\text { e } 4 \text { meses, } \\
\text { macho, } 4,7 \mathrm{~kg} \\
\text { (caso 2) }\end{array}$ & $\begin{array}{l}\text { Imobilização } \\
\text { com pino IM e tala; } \\
\text { realizada duas } \\
\text { intervenções, totalizando } \\
8 \text { meses de evolução. }\end{array}$ & $\begin{array}{l}\text { Não-união de fratura do terço } \\
\text { médio-distal do rádio e ulna } \\
\text { esquerdos, com pino IM } \\
\text { Steinmann posicionado no } \\
\text { fragmento distal do rádio e sem } \\
\text { ultrapassar o foco de fratura. }\end{array}$ & $\begin{array}{l}3 \text { pinos } \\
\text { proximais e } 2 \\
\text { distais }\end{array}$ & 4 meses & $\begin{array}{l}\text { Excelente/ } \\
3 \text { meses }\end{array}$ \\
\hline $\begin{array}{l}\text { Poodle, } 1 \text { ano, } \\
\text { fêmea, } 4,5 \mathrm{~kg} \\
\text { (caso 3) }\end{array}$ & $\begin{array}{l}\text { Imobilização com pino } \\
\text { IM e posteriormente tala, } \\
\text { totalizando } 6 \text { meses de } \\
\text { evolução }\end{array}$ & $\begin{array}{l}\text { Não-união hipertrófica } \\
\text { moderada do terço médio-distal } \\
\text { do rádio e ulna esquerdos, com } \\
\text { desvio do eixo ósseo em } \\
\text { incidência mediolateral. }\end{array}$ & $\begin{array}{l}3 \text { pinos } \\
\text { proximais e } 2 \\
\text { distais }\end{array}$ & $\begin{array}{l}4 \text { meses e } \\
\text { meio }\end{array}$ & $\begin{array}{l}\text { Excelente/ } 4 \text { anos e } 7 \\
\text { meses }\end{array}$ \\
\hline $\begin{array}{l}\text { Chiuahua, } 2 \\
\text { anos, macho, } \\
1,8 \mathrm{~kg} \\
\text { (caso 4) }\end{array}$ & $\begin{array}{l}\text { Tala por um período de } 3 \\
\text { meses. No intervalo de } 1 \\
\text { ano, foi tratado duas vezes } \\
\text { com fixador esquelético } \\
\text { externo devido à fratura } \\
\text { após quedas. }\end{array}$ & $\begin{array}{l}\text { Não-união oligotrófica de fratura } \\
\text { do terço médio-distal do rádio e } \\
\text { ulna direitos, com desvio do eixo } \\
\text { ósseo. }\end{array}$ & $\begin{array}{l}3 \text { pinos } \\
\text { proximais e } 2 \\
\text { distais }\end{array}$ & 4 meses & $\begin{array}{l}\text { Satisfatório/ } 2 \text { anos e } \\
4 \text { meses }\end{array}$ \\
\hline $\begin{array}{l}\text { Pastor Alemão, } \\
5 \text { anos, macho, } \\
33,6 \mathrm{~kg} \\
\text { (caso 5) }\end{array}$ & $\begin{array}{l}\text { Imobilização com pino } \\
\text { IM Steinmann por } 45 \\
\text { dias; realizadas duas } \\
\text { intervenções. }\end{array}$ & $\begin{array}{l}\text { Osteomielite com fratura } \\
\text { transversa simples do terço } \\
\text { médio-distal do rádio e ulna } \\
\text { esquerdos. Presença de pino IM } \\
\text { no rádio, com extremidade distal } \\
\text { longa e exposta. }\end{array}$ & $\begin{array}{l}3 \text { pinos } \\
\text { proximais e } 2 \\
\text { distais }\end{array}$ & 3 meses & Bom/ 5 anos \\
\hline $\begin{array}{l}\text { Fox } \\
\text { Paulistinha, } 7 \\
\text { meses, macho, } \\
4 \mathrm{~kg} \\
\text { (caso 6) }\end{array}$ & Tala por 2 meses & $\begin{array}{l}\text { Má-união de fratura terço } \\
\text { médio-distal do rádio e ulna } \\
\text { esquerdos, com desvio do eixo } \\
\text { ósseo em incidência } \\
\text { mediolateral. }\end{array}$ & $\begin{array}{l}4 \text { pinos } \\
\text { proximais e } 2 \\
\text { distais }\end{array}$ & 1 mês e meio & $\begin{array}{l}\text { Excelente/ } 7 \text { anos e } 7 \\
\text { meses }\end{array}$ \\
\hline $\begin{array}{l}\text { Sem raça } \\
\text { definida, } 3 \\
\text { anos e } 2 \\
\text { meses, } 15 \mathrm{~kg}, \\
\text { (caso } 7 \text { ) }\end{array}$ & $\begin{array}{l}\text { Imobilização com pino } \\
\text { IM e posteriormente tala } \\
\text { totalizando } 3 \text { meses de } \\
\text { evolução }\end{array}$ & $\begin{array}{l}\text { Fratura terço médio-distal do } \\
\text { rádio e ulna direitos com desvio } \\
\text { do eixo ósseo em incidência } \\
\text { mediolateral. }\end{array}$ & $\begin{array}{l}3 \text { pinos } \\
\text { proximais e } 2 \\
\text { distais }\end{array}$ & 2 meses & Bom/ 3 meses \\
\hline $\begin{array}{l}\text { Poodle, } 1 \text { ano e } \\
4 \text { meses, } \\
\text { macho, } 2,2 \mathrm{~kg} \\
\text { (caso } 8 \text { ) }\end{array}$ & $\begin{array}{l}\text { Imobilização com pino } \\
\text { IM por } 52 \text { dias. }\end{array}$ & $\begin{array}{l}\text { Fratura terço médio-distal do } \\
\text { rádio e ulna direitos, com } \\
\text { presença de fio IM de Kirschner } \\
\text { quebrado junto ao foco. }\end{array}$ & $\begin{array}{l}3 \text { pinos } \\
\text { proximais e } 2 \\
\text { distais }\end{array}$ & $\begin{array}{l}2 \text { meses e } \\
\text { meio }\end{array}$ & Excelente/4 anos \\
\hline
\end{tabular}

Ciência Rural, v.35, n.5, set-out, 2005. 


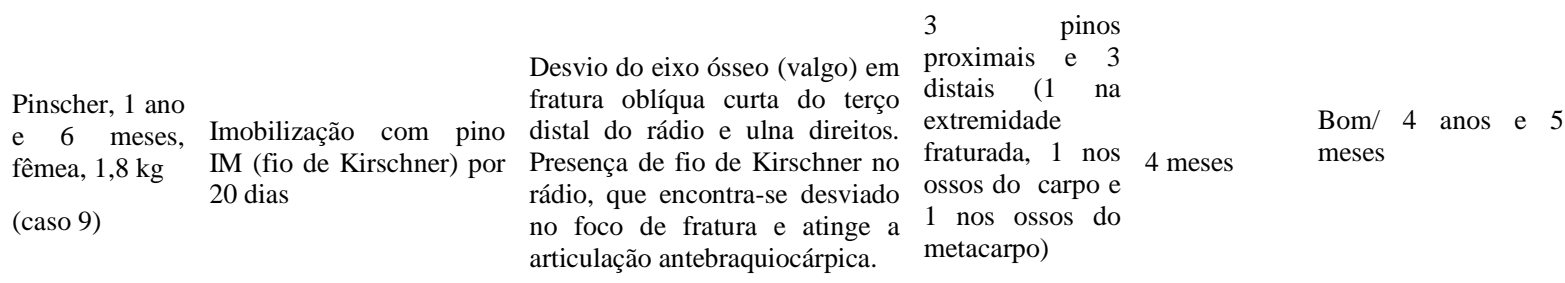

Fratura oblíqua curta do

\begin{tabular}{|c|c|c|c|c|c|c|}
\hline $\begin{array}{l}\text { Pinscher, } 6 \\
\text { meses, macho, } \\
2,2 \mathrm{~kg} \\
\text { (caso 10) }\end{array}$ & $\begin{array}{l}\text { Tala e fixador esquelético } \\
\text { externo, totalizando } 2 \\
\text { meses de evolução }\end{array}$ & $\begin{array}{l}\text { terço médio-distal do rádio e } \\
\text { ulna direitos com desvio do eixo } \\
\text { ósseo; pinos transfixantes } \\
\text { aplicados muito próximos ao } \\
\text { foco de fratura, estando } \\
\text { quebrado } 1 \text { de um total de } 5 \text {. }\end{array}$ & $\begin{array}{l}3 \\
\text { proximais } \\
\text { distais }\end{array}$ & $\begin{array}{l}\text { pinos } \\
\text { e } 2\end{array}$ & 3 meses & $\begin{array}{l}\text { Excelente/1 ano e } 7 \\
\text { meses }\end{array}$ \\
\hline
\end{tabular}

IM - intramedular

há possibilidade do desenvolvimento fratura iatrogênica (GORSE, 1998). Desta forma, estrategicamente empregouse nesses animais um posicionamento mais cranial, conforme indicação de WATERS et al. (1993).

Entre as vantagens citadas com relação ao uso de fixadores, uma das mais significativas em relação ao de resina acrílica-pino, refere-se à liberdade tanto no local de inserção do pino como na possibilidade do uso de pinos de diferentes diâmetros (OKRASINSKI et al., 1991; WATERS et al., 1993; LEWIS \& BLOOMBERG, 1994; HARARI et al., 1998). Isso é particularmente importante quando a extremidade distal do foco de fratura é muito curta e faz-se necessária à aplicação de pinos nos ossos do carpo e metacarpo para se obter estabilidade na montagem, como no caso 9.

No sistema comercial americano, são usados tubos de tamanhos pré-determinados, que, ao serem preenchidos pela resina, adquirem a resistência mecânica equivalente ao fixador K-E pequeno, médio ou grande (HULSE \& JOHNSON, 2002). Uma das desvantagens do método utilizado em relação ao americano é a não padronização de peso e resistência, que provavelmente foram superiores, visto a resina acrílica ter sido aplicada sobre as extremidades dobradas dos pinos de transfixação. Além disso, a equipe cirúrgica fica exposta aos odores da resina durante o seu preparo e polimerização (OKRASINSKI et al., 1991).

Para preservar a interface osso-pino e diminuir a morbidade do paciente, alguns cuidados devem ser tomados tanto na seleção do pino como no método de inserção(ANDERSON et al., 1997; HULSE \& JOHNSON, 2002). Utilizou-se um mínimo de dois e máximo de quatro pinos proximais e distais às extremidades fraturadas do rádio porque, segundo GORSE (1998), a colocação de três ou quatro pinos para cada segmento da fratura maximiza a rigidez da composição fixador-osso. Entretanto, o uso de mais de quatro pinos proporciona uma rigidez adicional mínima (LEWIS \& BLOOMBERG, 1994). O diâmetro do pino usado foi de no máximo $20 \%$ do diâmetro do osso, para aumentar a rigidez sem causar perda substancial da força cortical e para evitar a fratura iatrogênica (HARARI et al., 1998; HULSE \& JOHNSON, 2002).

Embora os pinos rosqueados, particularmente os de perfil positivo (GORSE, 1998), sejam os mais indicados quando se espera um tempo maior de permanência do fixador, como nos casos do presente experimento, eles não puderam ser empregados devido ao custo, uma vez que os cães pertenciam a proprietários com baixo poder aquisitivo. Sendo assim, uma das estratégias para minimizar o afrouxamento prematuro (ANDERSON et al, 1997; HARARI et al., 1998) foi a inserção dos pinos lisos em sua maioria angulados em relação ao eixo longitudinal do osso. Embora o ideal seja a aplicação de pinos angulados em torno de $70^{\circ}$ (ANDERSON et al., 1997; HULSE \& JOHNSON, 2002), por vezes, isto não foi possível. No entanto, isso pode ser mais comprometedor em montagens unilaterais do que bilaterais. Alguns autores não recomendam a aplicação dos pinos de forma inteiramente manual por causa da oscilação (GORSE, 1998; HARARI et al., 1998). Contudo, os autores do presente relato têm utilizado o perfurador manual com manivela com bons resultados, especialmente em cães de porte pequeno, desde que se tomem cuidados como a manutenção da extremidade do pino curta durante a inserção, o pulso rígido e a não aplicação de força excessiva durante a penetração. 
O afrouxamento do pino é a maior complicação com o uso de fixadores esqueléticos externos e resulta de uma série complexa de eventos em cães. Caracteriza-se, muitas vezes, por claudicação aguda e, radiograficamente, por osteólise ao redor do pino e migração deste (HARARI et al, 1998). Nos presentes casos, notou-se que, clinicamente, o aumento de secreção nos pontos de emergência dos pinos, em geral, correspondia a osteólise radiográfica. Desta forma, uma das desvantagens do método em relação ao sistema K-E é a dificuldade de substituição do pino comprometido por outro (ROSS \& MATTHIESEN, 1993). Por outro lado, como referido por JOHNSON et al. (1989/1998), o afrouxamento do pino compromete a redução e a estabilidade nos estágios precoces da consolidação, sendo menos problemático quando o calo ósseo estiver presente, fato constatado nos casos clínicos estudados. Apenas nos casos 7 e 8, foi necessário o uso adicional de tala para que se obtivesse a finalização da consolidação da fratura. Visto que o suporte de peso estimula a consolidação (WATERS et al., 1993) e como já havia um bom calo periosteal, a tala foi colocada de forma a permitir total apoio do membro ao solo. Vale referir que outro fator associado ao aumento de secreção nos locais de emergência é o movimento pele-pino (HARARI e al., 1998), que pode ser reduzido pelo uso de gaze interposta ao redor dos pinos, como empregado nos presentes casos.

O padrão da consolidação de fraturas tratadas com fixador esquelético externo varia de união direta a grande formação de calo por união indireta, sendo dependente do tipo de fratura e rigidez do fixador (JOHNSON et al., 1989/1998). Em todos os casos, a consolidação foi por calo periosteal, porém de volume discreto a moderado, indicando boa estabilidade da montagem. O enxerto esponjoso autólogo fresco foi usado com o intuito de promover estímulo à consolidação e, conseqüentemente, reduzir a carga mecânica imposta ao fixador (RUDD \& WHITEHAIR, 1992; WATERS et al., 1993). Pelos tipos de complicações e tempo de permanência do fixador (mínimo de 1 mês e meio e máximo de 5 meses), provavelmente sem o seu emprego, o índice de insucesso seria alto. Embora a maioria dos casos (60\%) tenha apresentado resultado funcional excelente, $30 \%$ foi bom e $10 \%$ satisfatório. A gravidade da lesão inicial e o tipo de intervenção cirúrgica prévia provavelmente contribuíram para estes resultados.

Foi possível concluir que o fixador esquelético pino-resina, configuração tipo II, coadjuvado pelo enxerto esponjoso autólogo, é uma opção simples, eficaz e de baixo custo para o tratamento das complicações secundárias à imobilização inadequada de fraturas do rádio e ulna em cães.

\section{FONTESDEAQUISIÇÃO}

\author{
a Perfurador hand drill - Ortosintese - Rua Prof. \\ Affonso José Fioravanti, no 63 - São Paulo, SP. \\ b Acrílico auto-polimerizante (Jet) - Artigos \\ Odontológicos Clássico - Av. Diógenes Ribeiro de Lima, ${ }^{\circ}$ \\ 2720 - São Paulo, SP.
}

\section{REFERÊNCIAS}

ANDERSON, M.A. et al. Improving pin selection and insertion technique for external skeletal fixation. Compend Contin Educ Pract Vet, v.19, n.4, p.485-494, 1997.

BOUDRIEAU, R.J. Fractures of the radius and ulna. In: SLATTER, D.H. Textbook of small animal surgery. 3.ed. Philadelphia : Saunders, 2002. Chap.139, p.1953-1973.

FOX, S.M. et al. Antebrachial deformities in the dog: treatment with external fixation. J Small Anim Pract, v.36, n.7, p.315$320,1995$.

GORSE, M.J. Using external skeletal fixation for fractures of the radius and ulna and tibia. Vet Med, v.93, p.463-467, 1998.

HARARI, J. et al. Principles of external skeletal fixation in small-animal surgery. Vet Med, v.93, p.445-453, 1998.

HULSE, D.A.; JOHNSON, A.L. Fundamentals of orthopedic surgery and fracture management. In: FOSSUM, T. Small animal surgery. 2.ed. St. Louis : Mosby, 2002. Chap.33, p.821-900.

JOHNSON, A.L. et al. Radial and tibial fracture repair with external skeletal fixation. Effects of fracture, type, reduction, and complications on healing. Vet Surg, v.18, n.5, p.367372, 1989.

JOHNSON, A.L. et al. Biomechanics and biology of frature healing with external skeletal fixation. Compend Contin Educ Pract Vet, v.20, n.4, p.487-502, 1998.

LAPPIN, M.R. et al. Fractures of the radius and ulna in the dog. J Am Anim Hosp Assoc, v.19, n.5, p.643-650, 1983.

LEWIS, D.D.; BLOOMBERG, M.S. Fijación ósea externa. Waltham Focus, v.4, n.4, p.9-18, 1994.

LINCOLN, J.D. Treatment of open, delayed union, and nonunion fractures with external skeletal fixation. Vet Clin North Am : Small Anim Pract, v.22, n.1, p.195-206, 1992.

OKRASINSKI, E.B. et al. Biomechanical evaluation of acrylic external skeletal fixation. J Am Vet Med Assoc, v.199, n.11, p.1590-1593, 1991.

ROSS, J.T.; MATTHIESEN, D.T. The use of multiple pin and methylmethacrylate external skeletal fixation for the treatment of orthopaedic injuries in the dog and cat. Vet Comp Orthop Traum, v.6, p.115-121, 1993.

RUDD, R.G.; WHITEHAIR, J.G. Fractures of the radius and ulna. Vet Clin North Am : Small Anim Pract, v.22, n.1, p.135-148, 1992.

WATERS et al. Treatment of common forelimb fractures in miniature- and toy-breed dogs. J Am Anim Hosp Assoc, v.29, p.442-448, 1993.

Ciência Rural, v.35, n.5, set-out, 2005. 